This item was submitted to Loughborough's Research Repository by the author.

Items in Figshare are protected by copyright, with all rights reserved, unless otherwise indicated.

\title{
Associations between retirement reasons, chronic pain, athletic identity, and depressive symptoms among former professional footballers
}

PLEASE CITE THE PUBLISHED VERSION

https://doi.org/10.1080/17461391.2017.1371795

\section{PUBLISHER}

(C) European College of Sport Science. Published by Taylor \& Francis

\section{VERSION}

AM (Accepted Manuscript)

\section{PUBLISHER STATEMENT}

This work is made available according to the conditions of the Creative Commons Attribution-NonCommercialNoDerivatives 4.0 International (CC BY-NC-ND 4.0) licence. Full details of this licence are available at: https://creativecommons.org/licenses/by-nc-nd/4.0/

\section{LICENCE}

CC BY-NC-ND 4.0

\section{REPOSITORY RECORD}

Sanders, George, and Clare Stevinson. 2019. "Associations Between Retirement Reasons, Chronic Pain, Athletic Identity, and Depressive Symptoms Among Former Professional Footballers". figshare. https://hdl.handle.net/2134/26660. 
Associations between retirement reasons, chronic pain, athletic identity and depressive symptoms among former professional footballers

Word count: 2893 (excluding title page, abstract, references, and tables) 


\section{Abstract}

2 Background: Retirement from professional sport has been recognised as a major

3 psychological stressor, and there is a need to identify factors that increase the risk of mental

4 health problems after career termination. The current study examined associations between

5 career-ending injury, chronic pain, athletic identity and depressive symptomology in retired

6 professional footballers. Methods: A cross-sectional study was performed with 307 retired

7 male footballers who had played within a professional United Kingdom league. Participants

8 completed measures of depressive symptoms (Short Depression-Happiness Scale), chronic

9 pain (Pain Intensity Numerical Rating Scale), and athletic identity (Athletic Identity

10 Measurement Scale), and reported their reasons for retirement. Results: A total of 48

11 participants (16\%) met the cut-off score for possible cases of clinically-relevant depression.

12 These participants were more recently retired, and had higher athletic identity than those

13 without depressive symptoms. Former players with depressive symptoms were more likely

14 to cite injury as a retirement reason, and report higher levels of ongoing injury-related pain.

15 Multivariate logistic regression revealed that presence of depressive symptoms was

16 independently associated with retirement through injury $(\mathrm{OR}=3.44 ; 95 \% \mathrm{CI}=1.39,8.51)$,

17 higher pain levels $(\mathrm{OR}=1.38 ; 95 \% \mathrm{CI}=1.02,1.86)$, and increased athletic identity $(\mathrm{OR}=$

18 1.28; 95\% CI = 1.14, 1.44). Conclusions: Career-ending injury is strongly associated with

19 higher odds of depressive symptomology during retirement, while experiencing chronic

20 pain, and maintaining a high sense of athletic identity, are additional potential contributors.

21 [abstract word count: 233]

23 Key words: football; retirement; depression; injury; pain; athletic identity 


\section{Introduction}

2 According to the Professional Footballers Association (2015) as many as 900 professional

3 players retire each year from leagues in England. Retirement from sport has been recognised

4 as a significant career transition that is associated with decreased psychological wellbeing

5 for some athletes (Wylleman, Alfermann, \& Lavallee, 2004). This has been particularly

6 noted when retirement is perceived as involuntary, that is forced, for example due to injury,

7 rather than through personal choice (Kuettel, Boyle, \& Schmid, 2017).

8 Recent studies in retired footballers have highlighted the prevalence of psychological

9 problems, and revealed the uncertainty over the role of injury as a contributor. A preliminary

10 study including an international sample of 104 retired professional footballers found that

11 symptoms of anxiety or depression were reported by 39\% of respondents (Gouttebarge,

12 Frings-Dresen, \& Sluiter, 2015). A subsequent study of 219 former players across 11

13 countries had similar results with 35\% reporting anxious or depressed symptoms

14 (Gouttebarge, Aoki, \& Kerkhoffs, 2016). However, presence of these symptoms was not

15 associated with the severity of previous injuries, or the number of surgeries undergone.

16 Another study included 220 retired European footballers as part of a sample of 602 former

17 elite athletes across five sports to examine the relationship between the presence of

18 osteoarthritis and symptoms of mental disorders (Schuring et al., 2016). Overall there was an

19 association between osteoarthritis and distress, sleep problems, and adverse alcohol use, but

20 not anxiety/depression. Among the footballers, no associations were observed between

21 osteoarthritis and any of the symptoms measured. A more pertinent factor may be the

22 experience of chronic pain rather than the history of injury or presence of musculoskeletal

23 conditions per se. A strong association has been demonstrated between depression and pain 
1 symptoms in general populations (Ohayon \& Schatzberg, 2003; Ohayon \& Schatzberg,

2 2010). An earlier study of the long-term health of 284 former professional footballers in the

3 United Kingdom revealed that $49 \%$ had been diagnosed with osteoarthritis, and $28 \%$ took

4 pain medication for football injuries (Turner, Barlow, \& Heathcote-Elliott, 2000). Pain or

5 discomfort was frequently reported across the sample, but among significantly more former

6 players with osteoarthritis (89\%) than those without (60\%). Similarly, symptoms of

7 anxiety/depression were reported by more participants with osteoarthritis (37\%), than by

8 those without arthritis (19\%), although the relationship between pain and psychological

9 symptoms was not examined. These results suggest that chronic pain may be an important

10 variable to examine in the attempt to further understanding of the factors contributing to

11 psychological health after retirement.

13 athletic identity is an important construct associated with psychological wellbeing after

14 retirement. Athletic identity represents an element of self-concept among sportspeople and

15 refers to the degree to which individuals identify with their athlete role, and includes

16 perceived values and social networks (Brewer, Van Raalte, \& Linder, 1993). Longitudinal

17 research with elite athletes suggests that athletic identity generally declines towards

18 retirement, and is lower among former athletes who experienced a positive adjustment to

19 career termination (Martin, Fogarty, \& Albion, 2014). However, where careers were

20 terminated involuntarily, those displaying high levels of athletic identity were more likely to

21 experience negative reactions including dissatisfaction, depression, and loneliness

22 (Alfermann, Stambulova, \& Zemaityte, 2004; Lally, 2007). 
The current study aimed to increase understanding of the determinants of depressive

2 symptoms among male retired professional footballers in the United Kingdom by

3 specifically examining the relationship with retirement reasons, chronic pain, and athletic

4 identity. Based on the existing literature in football and other sports, it was hypothesised that

5 participants reporting depressive symptoms would be more likely to have retired for injury-

6 related reasons, experience chronic pain, and have high levels of athletic identity.

\section{Methods}

9 Design and participants

10 Ethical approval was provided by Loughborough University Ethics Approvals (Human

11 Participants) Sub-Committee (SSEHS-28415) to perform a cross-sectional study

12 administered online of former professional male footballers. Access to participants through

13 official player organisations was not possible, making a formal sampling frame unavailable

14 for recruitment. Therefore social media sources were used to circulate links to the study

15 information to former players using purposive and snowball sampling. To be eligible for

16 inclusion, participants had to be male, 18 years old or over, and have previously competed in

17 a professional football league in the United Kingdom. Participation was voluntary with no

18 incentives provided. Measures

21 The online questionnaire was administered via Bristol Online Survey software, with 22 participants providing informed consent online and completing measures anonymously. 
1 Participant information collected was current age, duration of professional football career,

2 level of play (highest league played), year of retirement, and reasons for retirement. Depressive symptoms were assessed through the Short Depression-Happiness Scale

4 (SDHS; Joseph, Linley, \& Harwood, 2004). This measure asks participants to judge their

5 feelings over the past seven days with reference to six items representing depression (e.g. 'I

6 felt that life was meaningless') and happiness (e.g. 'I felt happy'), scored on a four-point (0-

$7 \quad 3$ ) Likert scale. Total possible scores range from 0 to 18 , with lower scores indicating greater

8 depression. The SDHS has shown acceptable levels of internal consistency (Cronbach's $\alpha=$

$9 \quad 0.77$ to 0.92$)$ and test-retest reliability $(r=0.68)$ over two weeks (Joseph et al., 2004).

10 Convergent validity was demonstrated with correlations of 0.68 with the Beck Depression

11 Inventory (Beck, Rush, Shaw, \& Emery, 1978), and 0.74 with the depression scale of the

12 Crown-Crisp Experiential Index (Crown \& Crisp, 1979). Based on a comparison of scores

13 on the Beck Depression Inventory (Beck et al., 1978), a total below 10 on the SDHS is

14 recommended as the cut-off indicating possible cases of clinically relevant depression

15 (Joseph et al., 2004). Cronbach’s alpha in the current study was 0.87.

16 Pain levels were assessed with the 11-point pain intensity numerical rating scale (PI-

17 NRS; Farrar, Young, LaMoreaux, Werth, \& Poole, 2001). Respondents were asked to report 18 the intensity of any pain attributable to past football injuries on a scale anchored by "no 19 pain” (score of 0 ) and “worst imaginable pain” (score of 10). High test-retest reliability ( $\mathrm{r}=$ 20 0.96) and construct validity $(r=0.86)$ has been reported for the PI-NRS (Hawker, Mian, 21 Kendzerska, \& French, 2011).

22 Athletic identity was assessed via the 10-item Athletic Identity Measurement Scale 23 (AIMS; Brewer et al., 1993). Respondents indicate their level of agreement with ten 
1 statements on a 5-point Likert scale ranging from 1 (strongly disagree) to 5 (strongly agree).

2 The total score ranges from 10 to 50, with higher scores indicating stronger identification

3 with the athletic role. Sound psychometric properties were demonstrated of the AIMS

4 (Brewer et al., 1993), with good internal consistency (Cronbach $\alpha=0.93$ ), test-retest

5 reliability $(r=0.89)$, and convergent validity $(r=0.83)$ against a measure of perceived

6 importance of sport competence (Fox \& Corbin, 1989). Cronbach’s alpha in the current

7 study was 0.90 .

8 Reasons for retirement were ascertained by asking participants to select from a list of

9 five common reasons for retirement (shown in Table I) identified from previous research of

10 former UK footballers (Drawer \& Fuller, 2002). Multiple reasons could be selected, and

11 there was an option to indicate other reasons via a free-text box. They were also asked to

12 indicate one reason that they regarded as their main reason for retirement.

13 Data analysis

14 All data analyses were performed using IBM SPSS Statistics for Windows version 22.0

15 (IBM Corp, Armonk, NY). Descriptive statistics (frequency, mean, standard deviation) were

16 calculated for participant characteristics and measured variables. Participants were

17 dichotomised on possible depression status using the recommended cut-off score for the

18 SDHS ( $<10=$ cases with depressive symptoms; $\geq 10$ cases without depressive symptoms).

19 Differences between the two groups and standardised effect sizes were calculated using

20 independent samples $t$-tests and Cohen's $d$ for continuous variables, and Chi-square tests

$21\left(\chi^{2}\right)$ and phi coefficients $(\varphi)$ for categorical variables. Where significant differences were

22 identified, these variables were included as covariates in a multivariable logistic regression 
1 analysis. Odds ratios and confidence intervals were calculated to estimate the odds that

2 depression status varied due to differences in explanatory variables.

\section{Results}

5 In total, 307 retired professional footballers provided informed consent and completed

6 outcome measures. Participant characteristics are summarised in Table I. Mean age was 46.8

$7 \pm 15.7$ years, and the mean time elapsed since retiring was $21.2 \pm 14.6$ years. Injury was a

8 reason for retirement for 130 (42.3\%) participants, and was the main reason for 90 (29.3\%).

9 The most common sites of chronic pain from football injuries were knee (48.2\%), leg

10 (34.2\%), and groin (31.3\%).

11 A total of 48 participants (15.6\%) scored below the threshold on the SDHS indicating 12 possible clinically-relevant depressive symptoms. Differences between participants with and 13 without depressive symptoms for all variables are presented in Table I. Compared with the

14 majority of the sample, those with depressive symptoms were younger (mean age of 34.2

15 versus 49.2 years; $t=6.48, p<0.001 ; d=1.02$ ), more recently retired (mean time since

16 retirement 10.4 versus 23.5 years; $t=6.02, p<0.001 ; d=0.95$ ), and displayed higher

17 athletic identity (mean score of 38.9 versus $28.8 ; t=9.86, p<0.001 ; d=1.55$ ). They were

18 also more likely to cite injury as one reason for retiring $\left(79.2 \%\right.$ versus $35.5 \% ; \chi^{2}=31.60, p$

$19<0.001, \varphi=0.32)$, and the main reason for retirement $\left(72.9 \%\right.$ versus $21.2 \% ; \chi^{2}=52.20, p<$

20 0.001, $\varphi=0.41$ ). For those retiring mainly due to injury, the prevalence of depressive

21 symptoms was 38.9\%. Finally, presence of ongoing injury-related pain was reported by more 22 participants with depression symptoms than those without $\left(95.8 \%\right.$ versus $63.7 \% ; \chi^{2}=19.45$, $23 p<0.001, \varphi=0.25$ ), and pain intensity was greater among this group (mean of 5.1 versus 
$13.0 ; t=6.03, p<0.001 ; d=0.95)$. Age at retirement and career duration were not associated

2 with depressive symptoms.

3 Four significant variables from the univariate analysis (time since retirement, injury

4 as a retirement reason, pain intensity, and athletic identity) were included as covariates in the

5 multivariable logistic regression analysis to examine the independent associations with

6 depressive symptoms. Since age and time since retirement were strongly correlated $(r=0.94$;

$7 \mathrm{p}<0.001$ ), only time since retirement was included in the multivariable analysis.

9 [INSERT TABLE I HERE]

11 Table II shows the odds ratios and 95\% confidence intervals for each variable.

12 Significant positive relationships for injury as a retirement reason, chronic pain, and athletic

13 identity were observed. In particular, the odds of being depressed were increased by 3.44

14 (95\% CI: 1.39, 8.51) for those retiring due to injury. Chronic pain increased the odds of

15 depression by a factor of 1.38 (95\% CI: 1.02, 1.86) for each unit increase in intensity.

16 Similarly, each unit increase in athletic identity score was associated with a 1.28 (95\% CI:

$171.14,1.44)$ increase in the odds of depression.

18

[INSERT TABLE II HERE]

20

\section{Discussion}

22 This study examined the psychological wellbeing of retired professional footballers, and

23 some of the factors associated with experiencing depression symptomology. The results 
1 suggested that $16 \%$ of the sample may have been experiencing clinically-relevant depressive

2 symptoms, and this was associated with retiring through injury, experiencing chronic pain,

3 and having higher athletic identity.

4 The proportion of possible cases of depression symptoms observed here is higher

5 than the 3\% prevalence rate of depressive episodes reported among the general adult male

6 population in England in the Adult Psychiatric Morbidity Survey (McManus, Bebbington,

7 Jenkins, \& Brugha, 2016). Direct comparisons are not meaningful since the current study

8 was not designed to ascertain prevalence, and used a different detection method (i.e. a self-

9 reported screening tool versus structured interviews). Nonetheless, the findings are

10 compatible with evidence suggesting that professional athletes may be at increased risk of

11 depressive symptoms after retirement (Gouttebarge et al., 2016; Schuring et al., 2016).

12 Notably, a previous international study by Gouttebarge et al. (2015) reported symptoms of

13 anxiety or depression to be more prevalent among former footballers than current players

14 (39\% versus 26\%).

15 Career-ending injury and chronic pain

16 In line with the findings of a previous study of retired British footballers that reported

17 anxiety/depression symptoms in 37\% of players with an osteoarthritis diagnosis (Turner et

18 al., 2000), the current study identified depressive symptoms among 39\% of those who had

19 retired mainly due to injury. The regression analysis indicated that involuntary retirement of

20 this nature was strongly associated with depressive symptoms, with the odds three times

21 higher than for non-injury reasons. As well as terminating sporting careers, injuries can lead

22 to long-term pain. In an earlier study of retired British professional footballers by Drawer

23 and Fuller (2001), 80\% reported some degree of pain during daily activities. As with the 
1 current study, the knee was the most common pain location. Pain is a recognised correlate of

2 depression (Bair, Robinson, Katon, \& Kroenke, 2003), and in this study its presence

3 significantly increased the odds of reporting depressive symptoms. These results are

4 compatible with a study of 1617 retired professional American footballers, which recorded a

5 similar proportion of possible depression cases (15\%) based on a self-report screening tool

6 (Schwenk, Gorenflo, Dopp, \& Hipple, 2007). Furthermore, 29\% of the study sample retired

7 due to injury, and experiencing chronic pain was strongly associated with depression status.

8 Studies in general population have also demonstrated the relationship between pain and

9 depression. Among 18,980 European adults, the odds of a depression diagnosis for those

10 reporting chronic pain was more than three times higher than for those without pain (Ohayon

11 \& Schatzberg, 2003).

12 Importance of athletic identity

13 The strength of athletic identity has been shown to predict difficulties with the

14 emotional adjustment to career termination across a range of sports (Kuettel et al., 2017;

15 Ronkainen, Kavoura, \& Ryba, 2016; Willard \& Lavallee, 2016). In the current study athletic

16 identity was associated with depressive symptomology among retired football players. The

17 high profile status of footballers and media constructions of them as sporting heroes can lead

18 to strongly defined athletic identities (Lines, 2001). This was illustrated in a study of youth

19 footballers in professional academies, where even at age 16 years, players had developed

20 high levels of athletic identity (Mitchell et al., 2014). In another study involving interviews

21 with young footballers who were not selected for professional contracts, having a strong

22 athletic identity was a contributor to experiencing emotional distress when released (Brown

23 \& Potrac, 2009). The current findings provide further support for the difficulties involved for 
1 some individuals in adjusting to a different lifestyle after careers are terminated when their

2 sense of identity is closely tied to their athletic status (Kuettel et al., 2017).

3 Considerations for provision of player welfare services

$4 \quad$ Previous studies have shown that key negative influences on successful transitions

5 out of sport include low educational attainment, inadequate vocational and life skill

6 development, and limited career planning (Park, Lavallee, \& Tod, 2013). Young footballers

7 in particular report that the commitment required to achieve, and maintain, professional

8 status, often overrides their attention to educational or vocational development, leaving

9 players ill-equipped for life after football (Parker, 2000). A study of retired UK footballers in

10 2002, revealed high levels of dissatisfaction with the educational and welfare services

11 available during their careers to prepare for retirement (Drawer \& Fuller, 2002).

One successful example of an intervention addressing adjustment to career

13 termination involved British professional footballers at the point of retirement (Lavallee,

14 2005). The programme involved assessment of life events and counselling to help develop

15 coping skills, and led to significant improvements in psychological adjustment outcomes,

16 compared with a control group. Other programmes have been implemented at earlier stages,

17 before retirement is reached, to ensure that the support provided is proactive (e.g. education

18 and employment opportunities), as well as reactive (e.g. coping skills, emotional support)

19 (Park, Lavallee, and Tod, 2012). Evidence-based interventions of this nature are increasingly

20 being implemented within professional sport, including football. Within the United

21 Kingdom, both the English and Scottish Professional Football Associations dedicate

22 considerable efforts to raising awareness of mental illness, and providing resources and 
1 support services for current and former players (Professional Footballers Association, 2016;

2 Professional Footballers Association Scotland, 2016).

3 Study limitations

4 It is important to note several limitations of this research. Notably, the cross-sectional

5 design of the study ensures that the findings represent associations between depressive

6 symptoms and the other variables, rather than imply a causal relationship. Furthermore, the

7 number of cases identified was based on reaching a specific score on a screening measure to

8 indicate possible clinically-relevant symptoms, rather than an actual diagnosis of a

9 depressive disorder. Self-report screening instruments generally overestimate the likelihood

10 of depression compared with a criterion-based diagnosis based on a structured clinical

11 interview (Valenstein, Vijan, Zeber, Boehm, \& Buttar, 2001).

An additional limitation concerns the purposeful recruitment process that prevents

13 the calculation of a precise response rate, and may limit the representativeness of the sample.

14 Nonetheless, key characteristics of participants in this study such as age, retirement age, and

15 the percent reporting career-ending injury were very similar to those in the earlier survey of

16 retired UK professional footballers recruited through a player union (Drawer \& Fuller,

17 2001). Finally, it is also worth noting that only a limited range of participant characteristics

18 were collected for this study. It is possible that other variables such as family history of

19 mental disorders, marital status, employment status, or educational achievements would be

20 associated with depressive symptoms. 


\section{Conclusion}

2 This study contributes to the growing body of evidence on mental health problems following

3 retirement from professional football. Findings suggest that a notable proportion of former

4 players may be experiencing clinically-relevant depressive symptomology, and that career-

5 ending injury significantly increases this risk. Intensity of chronic pain, and athletic identity

6 are additional potential contributors, and are factors to consider in the provision of support

7 services for former players.

8

9

10

11

12

13

14

15

16

17

18

19

20

21

22 


\section{References}

Alfermann, D., Stambulova, N., \& Zemaityte, A. (2004). Reactions to sport career termination: A cross-national comparison of German, Lithuanian, and Russian athletes. Psychology of Sport and Exercise, 5(1), 61-75. doi:10.1016/S1469-0292(02)00050-X

Bair, M. J., Robinson, R. L., Katon, W., \& Kroenke, K. (2003). Depression and pain comorbidity: A literature review. Archives of Internal Medicine, 163(20), 2433-2445. doi:10.1001/archinte.163.20.2433

Beck, A. T., Rush, A. J., Shaw, B. F., \& Emery, G. (1979). Cognitive therapy of depression: A treatment manual. New York: Guilford.

Brewer, B. W., Van Raalte, J. L., \& Linder, D. E. (1993). Athletic identity: Hercules' muscles or Achilles heel? International Journal of Sport Psychology, 24(2), 237-254.

Brown, G., \& Potrac, P. (2009). 'You’ve not made the grade, son’: Deselection and identity disruption in elite level youth football. Soccer \& Society, 10(2), 143-159. doi:10.1080/14660970802601613

Crown, S., \& Crisp, A. H. (1979). Manual of the Crown-Crisp Experiential Index. London: Hodder and Stoughton.

Drawer, S., \& Fuller, C. W. (2001). Propensity for osteoarthritis and lower limb joint pain in retired professional soccer players. British Journal of Sports Medicine, 35(6), 402-408. pmid:11726474

Drawer, S., \& Fuller, C. W. (2002). Perceptions of retired professional soccer players about the provision of support services before and after retirement. British Journal of Sports Medicine, 36(1), 33-88. pmid:11867490 
Farrar, J. T., Young, J. P., LaMoreaux, L., Werth, J. L., \& Poole, R. M. (2001). Clinical importance of changes in chronic pain intensity measured on an 11-point numerical pain rating scale. Pain, 94(2), 149-158. doi:10.1016/S0304-3959(01)00349-9

Fox, K. R., \& Corbin, C. B. (1989). The Physical Self-Perception Profile: development and preliminary validation. Journal of Sport and Exercise Psychology, 11(4), 408-430. doi:10.1123/jsep.11.4.408

Gouttebarge, V., Aoki, H., \& Kerkhoffs, G. (2015). Prevalence and determinants of symptoms related to mental disorders in retired male professional footballers. Journal of Sports Medicine and Physical Fitness, 56, 648-654. Retrieved from:

http://www.minervamedica.it/en/journals/sports-medphysical fitness/article.php?cod=R40Y9999N00A150079

Gouttebarge, V., Frings-Dresen, M. H. W., \& Sluiter, J. K. (2015). Mental and psychosocial health among current and former professional footballers. Occupational Medicine, 65(3), 190-196. doi:10.1093/occmed/kqu202

Hawker, G. A., Mian, S., Kendzerska, T., \& French, M. (2011). Measures of adult pain: Visual Analog Scale for Pain (VAS Pain), Numeric Rating Scale for Pain (NRS-Pain), McGill Pain Questionnaire (MPQ), Short-Form McGill Pain Questionnaire (SF-MPQ), Chronic Pain Grade Scale (CPGS), Short Form-36 Bodily Pain Scale (SF-36 BPS), and Measure of Intermittent and Constant Osteoarthritis Pain (ICOAP). Arthritis Care \& Research, 63(S11), S240-S252. doi:10.1002/acr.20543/full Joseph, S., Linley, P. A., Harwood, J., Lewis, C. A., \& McCollam, P. (2004). Rapid assessment of well-being: The Short Depression-Happiness Scale (SDHS). Psychology 
and Psychotherapy: Theory, Research and Practice, 77(4), 463-478. doi:10.1348/1476083042555406

Kuettel, A., Boyle, E., \& Schmid, J. (2017). Factors contributing to the quality of the transition out of elite sports in Swiss, Danish, and Polish athletes. Psychology of Sport and Exercise, 29, 27-39. doi:10.1016/j.psychsport.2016.11.008

Lally, P. (2007). Identity and athletic retirement: A prospective study. Psychology of Sport and Exercise, 8(1), 85-99. doi:10.1016/j.psychsport.2006.03.003

Lavallee, D. (2005). The effect of a life development intervention on sports career transition adjustment. Sport Psychologist, 19(2), 193-202. doi:10.1123/tsp.19.2.193

Lines, G. (2001). Villains, fools or heroes? Sports stars as role models for young people. Leisure Studies, 20(4), 285-303. doi:10.1080/02614360110094661

Martin, L. A., Fogarty, G. J., \& Albion, M. J. (2014). Changes in athletic identity and life satisfaction of elite athletes as a function of retirement status. Journal of Applied Sport Psychology, 26(1), 96-110. doi:10.1080/10413200.2013.798371

McManus, S., Bebbington, P., Jenkins, R., \& Brugha, T. (2016). Mental health and wellbeing in England: Adult Psychiatric Morbidity Survey 2014. Leeds: NHS Digital.

Mitchell, T. O., Nesti, M., Richardson, D., Midgley, A. W., Eubank, M., \& Littlewood, M. (2014). Exploring athletic identity in elite-level English youth football: a cross-sectional approach. Journal of Sports Sciences, 32(13), 1294-1299.

doi:10.1080/02640414.2014.898855

Ohayon, M. M., \& Schatzberg, A. F. (2003). Using chronic pain to predict depressive morbidity in the general population. Archives of general psychiatry, 60(1), 39-47. doi:10.1001/archpsyc.60.1.39 
Ohayon, M. M., \& Schatzberg, A. F. (2010). Chronic pain and major depressive disorder in the general population. Journal of psychiatric research, 44(7), 454-461. doi:10.1016/j.jpsychires.2009.10.013

Park, S., Lavallee, D., \& Tod, D. (2012). The development of an athlete career transition programme: A case study. Qualitative Methods in Psychology Bulletin, 13, 11-19.

Park, S., Lavallee, D., \& Tod, D. (2013). Athletes' career transition out of sport: a systematic review. International Review of Sport and Exercise Psychology, 6(1), 22-53. doi:10.1080/1750984X.2012.687053

Parker, A. (2000). Training for `Glory’, Schooling for `Failure’?: English professional football, traineeship and educational provision. Journal of Education and Work, 13(1), 61-76. doi:10.1080/136390800112231

Professional Footballers Association. (2015). Professional Footballers Association Transfer List. Retrieved from: http://www.thepfa.com/recruitment/transfer-list

Professional Footballers Association. (2016). Mental health and football. Retrieved from: https://www.thepfa.com/wellbeing

Professional Footballers Association Scotland. (2016). PFA Scotland Advice on Mental Health. Retrieved from: http://pfascotland.co.uk/advice/advice-on-mental-health/

Ronkainen, N. J., Kavoura, A., \& Ryba, T. V. (2016). A meta-study of athletic identity research in sport psychology: Current status and future directions. International Review of Sport and Exercise Psychology, 9(1), 45-64. doi:10.1080/1750984X.2015.1096414

Schuring, N., Aoki, H., Gray, J., Kerkhoffs, G.M., Lambert, M., \& Gouttebarge, V. (2016). Osteoarthritis is associated with symptoms of common mental disorders among former 
elite athletes. Knee Surgery, Sports Traumatology, Arthroscopy, 1-7.

doi:10.1007/s00167-016-4255-2doi:10.1007/s00167-016-4255-2

Schwenk, T.L., Gorenflo, D. W., Dopp, R. R., \& Hipple, E. (2007). Depression and pain in retired professional football players. Medicine \& Science in Sports \& Exercise, 39(4), 599-605. doi:10.1249/mss.0b013e31802fa679

Turner, A. P., Barlow, J. H., \& Heathcote-Elliott, C. (2000). Long term health impact of playing professional football in the United Kingdom. British Journal of Sports Medicine, 34(5), 332-336. pmid:11049141

Valenstein, M., Vijan, S., Zeber, J. E., Boehm, K., \& Buttar, A. (2001). The cost-utility of screening for depression in primary care. Annals of Internal Medicine, 134(5), 345-360. doi:10.7326/0003-4819-134-5-200103060-00007

Willard, V. C., \& Lavallee, D. (2016). Retirement experiences of elite ballet dancers: Impact of self-identity and social support. Sport, Exercise, and Performance Psychology, 5(3), 266-279. doi:10.1037/spy0000057

Wylleman, P., Alfermann, D., \& Lavallee, D. (2004). Career transitions in sport: European perspectives. Psychology of Sport and Exercise, 5(1), 7-20. doi:10.1016/S14690292(02)00049-3 
1 Table I. Participant characteristics and differences between depressed and non-depressed

2 retired footballers

\begin{tabular}{|c|c|c|c|}
\hline & $\begin{array}{l}\text { Total sample } \\
\qquad(\mathrm{n}=307)\end{array}$ & $\begin{array}{l}\text { Depressed } \\
(\mathrm{n}=48)\end{array}$ & $\begin{array}{r}\text { Non-depressed } \\
\qquad(\mathrm{n}=259)\end{array}$ \\
\hline Current age (years) & $46.8 \pm 15.7$ & $34.2 \pm 14.0$ & $49.2 \pm 14.9^{\mathrm{a}}$ \\
\hline Athletic identity (AIMS) & $30.4 \pm 7.5$ & $38.9 \pm 5.4$ & $28.8 \pm 6.7^{\mathrm{a}}$ \\
\hline Psychological wellbeing (SDHS) & $12.8 \pm 2.8$ & $8.0 \pm 1.1$ & $13.7 \pm 2.0^{z}$ \\
\hline Duration of playing career (years) & $6.7 \pm 3.7$ & $5.7 \pm 3.7$ & $6.9 \pm 3.6$ \\
\hline \multicolumn{4}{|l|}{ Highest level played* } \\
\hline Premier League & $59(19.2 \%)$ & $14(29.2 \%)$ & $45(17.4 \%)$ \\
\hline Football League Championship & 49 (16.0\%) & $10(20.8 \%)$ & $39(15.1 \%)$ \\
\hline Football League One & $60(19.5 \%)$ & $12(25.0 \%)$ & $48(18.5 \%)$ \\
\hline Football League Two & $82(26.7 \%)$ & $9(18.8 \%)$ & $73(28.2 \%)$ \\
\hline National League & 57 (18.6\%) & $3(6.3 \%)$ & $54(20.8 \%)$ \\
\hline Age at retirement (years) & $25.3 \pm 5.2$ & $23.8 \pm 5.4$ & $25.6 \pm 5.1$ \\
\hline Time since retirement (years) & $21.5 \pm 14.6$ & $10.4 \pm 12.3$ & $23.5 \pm 14.1^{\mathrm{a}}$ \\
\hline \multicolumn{4}{|l|}{ Reasons for retirement } \\
\hline Family/personal & $130(42.3 \%)$ & $5(10.4 \%)$ & $125(48.3 \%)^{\mathrm{a}}$ \\
\hline Injury & $130(42.3 \%)$ & $38(79.2 \%)$ & $92(35.5 \%)^{\mathrm{a}}$ \\
\hline Contract end & $128(41.7 \%)$ & $20(41.7 \%)$ & $108(41.7 \%)$ \\
\hline Declining ability & $121(39.4 \%)$ & $17(35.4 \%)$ & $104(40.2 \%)$ \\
\hline Age & $73(23.8 \%)$ & $5(10.4 \%)$ & $68(26.3 \%)$ \\
\hline Other & $5(1.6 \%)$ & $0(0.0 \%)$ & $5(1.9 \%)$ \\
\hline Total number of reasons & $1.9 \pm 0.9$ & $1.8 \pm 0.9$ & $1.9 \pm 1.0$ \\
\hline 1 & $136(44.3 \%)$ & $24(50.0 \%)$ & $112(43.2 \%)$ \\
\hline 2 & 79 (25.7\%) & $12(25.0 \%)$ & 67 (25.9\%) \\
\hline 3 & $76(24.8 \%)$ & $11(22.9 \%)$ & $65(25.1 \%)$ \\
\hline 4 & 15 (4.9\%) & $1(2.1 \%)$ & $14(5.4 \%)$ \\
\hline 5 & $1(0.3 \%)$ & $0(0.0 \%)$ & $1(0.4 \%)$ \\
\hline
\end{tabular}

Main reason for retirement 


\begin{tabular}{lrrr} 
Family/personal & $112(36.5 \%)$ & $2(4.2 \%)$ & $110(42.5 \%)^{\mathrm{a}}$ \\
Injury & $90(29.2 \%)$ & $35(72.9 \%)$ & $55(21.2 \%)^{\mathrm{a}}$ \\
Contract end & $36(11.7 \%)$ & $7(14.6 \%)$ & $29(11.2 \%)$ \\
Declining ability & $25(8.1 \%)$ & $2(4.2 \%)$ & $23(8.9 \%)$ \\
Age & $39(12.7 \%)$ & $2(4.2 \%)$ & $37(14.3 \%)$ \\
Other & $5(1.6 \%)$ & $0(0.0 \%)$ & $5(1.9 \%)$ \\
Presence of injury-related pain & $211(68.7 \%)$ & $46(95.8 \%)$ & $165(63.7 \%)^{\mathrm{a}}$ \\
Intensity of injury-related pain (PI-NRS) & $3.3 \pm 2.4$ & $5.1 \pm 1.5$ & $3.0 \pm 2.3^{\mathrm{a}}$ \\
Pain areas & & & \\
Knee & $148(48.2 \%)$ & $23(47.95)$ & $125(48.3 \%)$ \\
Leg & $105(34.2 \%)$ & $15(31.3 \%)$ & $90(34.7 \%)$ \\
Groin & $96(31.3 \%)$ & $11(22.9 \%)$ & $85(32.8 \%)$ \\
Hip & $79(25.7 \%)$ & $13(27.1 \%)$ & $66(25.5 \%)$ \\
Back & $63(20.5 \%)$ & $6(12.5 \%)$ & $57(22.0 \%)$ \\
Ankle & $60(19.5 \%)$ & $13(27.1 \%)$ & $47(18.1 \%)$ \\
Other & $44(14.3 \%)$ & $7(14.6 \%)$ & $37(14.3 \%)$ \\
\hline
\end{tabular}

1 Note: Data are mean \pm standard deviation or number (percent); *Current league system in

2 England, or equivalent earlier league systems or Scottish leagues; AIMS: Athletic Identity

3 Measurement Scale (scored 10-50); PI-NRS: Pain intensity numerical rating scale (scored 0-

4 10); SDHS: Short Depression Happiness Scale (scored 0-18); ${ }^{a}$ significant difference ( $\mathrm{p}<$

5 0.001) between depressed and non-depressed participants

6 
3 Table II. Odds of depression among retired professional footballers in association with 4 injury, pain, and athletic identity.

\begin{tabular}{lrr}
\hline & Odds ratio (95\% confidence intervals) & $\mathrm{p}$ \\
\hline Injury as retirement reason & $3.44(1.39,8.51)$ & 0.007 \\
Ongoing injury-related pain & $1.38(1.02,1.86)$ & 0.038 \\
Athletic identity & $1.28(1.14,1.44)$ & $<0.001$ \\
Years since retirement & $1.00(0.95,1.05)$ & 0.998 \\
\hline
\end{tabular}

5 